\title{
Organizational Communication in Practice: Does it Really Work?
}

Management Communication Quarterly 2019, Vol. 33(I) II2-116

(C) The Author(s) 2018

Article reuse guidelines: sagepub.com/journals-permissions DOI: $10.1177 / 0893318918808938$ journals.sagepub.com/home/mcq

\section{Silvia Gherardi}

At the beginning of 2018, I was reading Timothy Kuhn, Karen Lee Ashcraft, and François Cooren's book, when the Italian press published a news story that captured my attention. It was like the "world out there" was exemplifying what the authors were writing in their book. In the moment that I began to write my comments for the Forum, the story came back again to my mind, together with Horace's dictum "de te fabula narratur," meaning "about you the tale is told." Is it true that the story applies to this Forum as well? I shall narrate the story first and later see if and how the three versions of communicative relationality fit the story of Amazon and the electronic bracelet.

This is the story:

A huge debate was spread by rumor of the introduction of a wireless bracelet (a newly announced practice) at Amazon in Italy, where two new centers have been opened, for a total of 1,600 jobs. The bracelet, just patented in the US, had been designed to speed up the search for products stored in warehouses by employees, monitoring where they put their hands, vibrating to guide them in the right direction, and actually controlling all their movements. These details were to be transmitted on the minicomputer to the employee's wrist to take the goods, put it in a box, and switch to the next task. News of the patent appeared nearly in all newspapers, and almost all the exponents of the government and political parties reacted on social media, accusing the company of transforming their employees into new slaves of the capitalist system. Speaker of the House Laura Boldrini declared that "Working is not a crime," and called the proposal

University of Trento, Trento, Italy

\section{Corresponding Author:}

Silvia Gherardi, University of Trento, Via Verdi 26, 38I22, Trento, Italy.

Email: silvia.gherardi@unitn.it 
"degrading and offensive." Even the Prime Minister Paolo Gentiloni had a word in, saying that the challenge facing Italians was "quality jobs, not jobs with wristbands," and that Italy (differently from other countries) has labour laws that apply to every company. I remind the reader that, at that time, we had a leftist government.

What did a wireless bracelet - a new tool that was not yet put into useproduce? It made evident the sociomaterial relations in a texture of practices, producing an agencement in which the reputation of a company (that turns employees, paid little, into human robots who work near real robots, carrying out repetitive packaging tasks as quickly as possible, with the goal of achieving the ambitious delivery targets set by Amazon) was materialized. Moreover, the wireless bracelet produced the visibility of retail services that work with thin margins of profit, that minimize the cost of labor, that use work contracts that advise workers of their schedule time with little notice, that use algorithms to organize staffing according to optimization of the presence. We can see the bracelet's performativity not only in its capacity to make visible the connections between working and organizing practices, but also in its capacity to bring to light a question of moral (and not only economic) value. The bracelet made audible/readable/tangible/knowable a societal issue: What is the value of work? What is the meaning of work in a life and in a society? The political and ethical materialization of a practice within a society (and differently from other societies) is made sayable.

Obviously, I am aware that "my" story about Amazon and the electronic bracelet is already interpreted within my preferred interpretative categories: social practice, agencement, and sociomateriality. I do not belong to the community of communication scholars, and usually I do not use the category of communication for fear of a word worn out by its use. Nevertheless, I shall try to read this story with the three versions of communicative relationality that Kuhn, Ashcraft, and Cooren propose.

Version 1 is about communication as relating/linking/connecting, and it is rooted in the critique of the transmission/conduit view of communication, and of the interpretive/interactional view as well. In this version, the authors affirm that "communication is not only about people talking or about writing; it is also about connections, links, or relations that establish themselves between various beings." I think that the Amazon story may exemplify how a rumor (but was it a rumor rather than a nonaccomplished intention?) was transmitted and spread within a social network of people that used several material media of transmission, which materialized as activities of relating, linking, and connecting. The sociomateriality of the bracelet activated multiple connections, and it was a different "thing" within multiple relations: from being an instrument in a cooperative relation with humans, to being a 
material symbol of slavery, to being an issue of labor relations. Therefore, I conclude that Version 1 of communicative relationality may be well exemplified by this story.

Version 2 is about communication as writing the trajectory of practice. This version is rooted more explicitly in a critique of communication as meaning-making and argues for a focus on communicative practice as a site of struggles over meaning. Communication, thus, is seen as a performative practice whose logic unfolds into the future along a trajectory. I should say that Version 2 proposes to see communication as internal to the agencement of elements constitutive of a practice; and, therefore, the story of Amazon and the electronic bracelet is an easy example of how all the human and nonhuman elements get connected and achieve agency.

Version 3 is about communication as the constitutive transmission of affect. This version is grounded on the invitation to communication scholars to consider emotions differently. The authors are explicit in their differentiation of affect from emotions and feelings and stress also the materiality of affect as one vital force in world-making. In this case, their emphasis is on moving in the dual sense of moving us and moving among us. In the case of the third version as a lens for approaching the story of Amazon, I should say that affect is not immediately visible. We can (or cannot) perceive the intensity of the story, but I can suggest that affect was circulating among all the humans and nonhumans of the agencement put in motion by the rumor of the bracelet. However, I cannot "demonstrate" the work of affect in communicative relationality. This difficulty has to do with the elusiveness of the concept of affect and with what it means to do empirical research on affect.

I want to spend more words on Kuhn, Ashcraft, and Cooren's proposal of redefining affectively organizational communication, and the reason is not that I disagree with their view of it as a "process of encounter which makes social relations not only discursively sensible, but also materially senseable." On the contrary, I fully concur with such endeavor, and it gives me the opportunity to discuss how affect calls for an urge to invent "affective methodologies."

In fact, some caution is necessary in constructing "affect" as a research object. What might count as "empirical" within studies of affective communication practices? I do not believe that affect is an entity that can be captured as an it or a thing. Rather it is thought precisely as what exceeds the speaking subject, that is not easily seen, and that extends across time and space, in entangled processes. The challenge that the study of affect poses to organization studies is that it confounds many of our inherited and conventional dispositions toward empirical methodology. I do not have a quick "fix" for this 
problem, rather I would like to share my uneasiness, doubts, and passion for thinking "differently."

I try to further articulate my doubts. When the authors open this forum with the question - "what work can communication do?"- they articulate a question in the classical terms of practice theory. In fact, the formulation of such a question is an implicit invitation to leave behind questions about ontology (what communication is) for questions about performativity (what communication does). In other words, empirical ontologies are "done" in specific and situated epistemological practices, as John Law and Annemarie Mol, among many others, have illustrated. The passage from the singular "ontology" to the plural ontologies have marked the way for considering multiplicity and indeterminacy. Therefore, the reflection on how we do empirical research is an epistemological reflection about how "things" are made to matter and how epistemological relations make "things" acquire a situated position. This is my understanding of relational materialism, and I have the impression that this is a shared understanding with Kuhn, Ashcraft, and Cooren.

Nevertheless, I am surprised by their calling for an ontological turn as the basic assumption from which their argument develops. Moreover, they regard this "turn" as gaining steam across many fields. On the contrary, I thought that in organization studies and in science and technology studies, the debate on ontology was over and the issue was sent back to anthropology where it originated. The separation of ontology in the sense of essence (what there is) and epistemology in the sense of theory or model of what there is, may be misleading as the word ontology leads to thinking that explicit claims are being made about the nature of reality or being. I remember that in 2013, a special issue of Social Studies of Science was devoted to the turn to ontology where several authors were suggesting that our attention should always be directed to the webs of practices that enact a particular reality. This is also the main preoccupation within practice-based studies that interrogate how "things" come to be in the here and now of the deployment of epistemic practices. Personally, I prefer to turn to Barad's onto-epistemology (and also ethic-onto-epistemology) to stage our relationship with the world. Moreover, I want to stress how the authors, while calling for an ontological turn, explain it simply in terms of sociomateriality. Are they making an assumption on reality, or a plea against duality of categories and in favor of terms as Donna Haraway's natureculture (she was writing about the nonseparation of the material and the discursive back in 1985) and similar that have a long tradition in feminist studies?

Nevertheless, the reasons for noticing the call for an ontological turn is not so much to air my allergy to the term, as to notice how difficult it became to 
navigate in the midst of the several turns and the labels that are used to frame debates more and more enclosed within specific communities. To exemplify, we can see how the term "new materialisms" is used to frame: feminist new materialism, actor-network theory; affect theories; animal studies; new empiricisms, and finally, postconstructionism. If we are in a good mood, we can say that they share a concern for postepistemologies in social studies; but if we are not, then we fear remaining trapped in one turn for a couple of years, waiting (or working) for the new one. Is this a problem of communication? Is it a question of transmission, interpretation, communicative constitutive construction, or affective constitution of an epistemic field? I have no answer, only perplexities about how communication works. Can it be otherwise? My doubt does not originate from a wish to attain an unequivocal communication or similar rationalistic solutions for a "better communication." On the contrary, I have always been a convinced supporter of the merits of ambiguity, multiplicity, and deferral of meanings, therefore, I believe in discussions and conflicts over interpretations, in which I see mainly the potential of bringing further a conversation. Nevertheless, I feel the fatigue of communication when too much work has to be done to create a common ground. Is this fatigue linked to affective capitalism? Is this fatigue the work of a form of power that hits individuals at a nonconscious level and is transmitted in a viral form? Is this the work of communication that we may see in the Amazon story and that Kuhn, Ashcraft, and Cooren wish to make visible?

\section{Declaration of Conflicting Interests}

The author(s) declared no potential conflicts of interest with respect to the research, authorship, and/or publication of this article.

\section{Funding}

The author(s) received no financial support for the research, authorship, and/or publication of this article.

\section{Author Biography}

Silvia Gherardi is senior professor of sociology of work and organization at the Faculty of Sociology of the University of Trento, Italy, where she has been Director of the Research Unit on Communication, Organizational Learning, and Aesthetics (www.unitn.it/rucola) since 1993. Her last book (How to conduct a practice-based study: problems and methods, Edward Elgar, 2019, 2nd edition) is devoted to the discussion of methodologies for the empirical study of learning and knowing in working practices. A companion to the book has been published, co-authored with Antonio Strati (Learning and Knowing in Practice-based studies, Edward Elgar, 2012), and it proposes a selection of empirical papers from RUCOLA. 